\title{
The strength of weak embodiment
}

\author{
Carlos Tirado ${ }^{*}$, Omid Khatin-Zadeh ${ }^{2}$, Melina Gastelum ${ }^{3}$, Nathan Leigh Jones ${ }^{4}$, Fernando \\ Marmolejo-Ramos ${ }^{4}$
}

\begin{abstract}
While popular within some cognitive science approaches, the embodiment approach has still found resistance, particularly in light of evidence arguing against strong forms of embodiment. Among other things, the embodiment approach breaks away from the Cartesian ontology of the modulatory system. We claim that the advantages of the embodiment approach are: a) it grounds cognition into modal experience, b) it is harmonious with a materialist philosophy of mind (emergent materialism), and c) it is supported by experimental research in various fields. However, embodiment must still address abstractions, theoretical misunderstandings (representations vs non-representations) and neuroscientific findings that challenge the extension and relevance of sensorimotor properties into cognitive processes. While the strong version of embodiment is seriously challenged by conceptual and physiological setbacks, its weak version is supported by compelling evidence. We suggest future research focus on the psychophysiological bases of grounded cognition and redirect efforts towards the field of cross-modal correspondence.

\section{Resumen}

La teoría de la cognición corporeizada se separa de una ontología cartesiana basada en el sistema modular. Las ventajas del enfoque de la corporeización son: a) enraiza la cognición en la experiencia modal, b) está en armonía con una filosofía materialista de la mente (materialismo emergente), y c) está respaldada por la investigación experimental en varios campos. Sin embargo, la corporeización todavía debe dar cuenta de las abstracciones, los malentendidos teóricos (representación vs. no representación) y los hallazgos neurocientíficos que desafían la relevancia de las propiedades sensoriomotoras en los procesos cognitivos. Mientras que la versión fuerte de la corporeización se ve seriamente desafiada por los retos conceptuales y fisiológicos, su versión débil es respaldada por evidencia convincente. Sugerimos que la investigación futura se centre en las bases psicofisiológicas de la cognición corporeizada y redirija los esfuerzos hacia el campo de la correspondencia intermodal.
\end{abstract}

\section{Keywords}

the modulatory system; embodiment; emergent materialism; cross-modal correspondence.

Palabras Clave

sistema modular; corporeización; materialismo emergente; correspondencia intermodal.

${ }^{1}$ Gösta Ekman Laboratory, Department of Psychology, Stockholm University, Sweden.

${ }^{2}$ Department of English, Faculty of Humanities, Chabahar Maritime University, Chabahar, Iran.

${ }^{3}$ Department of Philosophy, National Autonomous University of Mexico, Mexico.

${ }^{4}$ School of Psychology, The University of Adelaide, Australia.

*Corresponding author: Carlos Tirado. carlos.tirado@psychology.su.se

Manuscript received 26-03-2018; revised 07-05-2018; accepted 20-06-2018.

\section{Introduction}

The purpose of this article is to work through some of the ideas, approaches, and limitations of the embodiment approach, taking into account both experimental research and philosophical notions. We also explore the traditional "mind-as-a-computer" approach, the weak or graded embodiment approach (cognition requires some sensorimotor activation) and the strong embodiment ap- proach (cognition cannot occur without sensorimotor activation), while comparing them with elemental findings in neuroscience and physiology. By returning to classical neuroscientific research, cross-modal correspondence experiments, and various concepts within the philosophy of mind (psychophysiological monism), we believe that we can clarify and enrich theoretical discussions. To this end, we seek to demonstrate that embodiment is currently the most suitable theoretical framework in which 
cognitive processes can be explored.

In recent years, there has been a growing tendency to conduct psychological research under an embodiment approach instead of the traditional 'mind-as-a-computer' approach. Barsalou (1999) found that cognitive processes have sensorimotor properties to some extent and require modal perception. Gallese and Lakoff (2005) also argue that knowledge itself is inherently embodied; that is, it is mapped and processed within the human sensory-motor system. These authors add that our sensory-motor system provides structure to conceptual content, and characterises the semantic content of concepts (see also Lakoff, 2014). According to some strong versions of this view, the act of imagining is a simulated form of action or perception, using many of the same sensory-motor networks (Gallese, 2003). Conversely, Fodor (1983) and Fodor and Pylyshyn (1981) propose a "mind-as-a-computer" approach, where peripheral cognitive processes are divided into modules that are independent of modal perception. From this perspective, concepts are conceived of as abstract and amodal entities that are represented in some "language of thought" (Fodor, 1975). This view holds that concepts are denoted by symbols and have the properties of productivity and compositionality (Gallese \& Lakoff, 2005). As Chemero and Silberstein (2008) posits, thoughts (propositional attitudes) are relationships between people and mental representations that stand for things in the world (their semantic properties). In this sense, any theory that takes cognition to involve semantically assessable internal entities is a form of representational theory of mind. While embodiment approaches are not necessarily anti-representationalist, radical approaches often are. This foray into embodied cognitive science appears to have began with the work of (Brooks, 1991) but there is also the claim (Chemero, 2009) that Gibson (1979), Barwise and Perry (1983) also have much to contribute to this domain.

There have been a great number of experimental research studies and theoretical discussions in the context of embodiment approaches, but there are still some points that call for clarification. Embodiment is a term assembled from a vast array of inter-disciplinary conceptions and variants and because of this, confusion and contradictions are to be expected. Therefore, it is necessary to organise the arguments and current evidence in favour of the embodiment approach.

\section{Modular system versus embodiment}

In years gone by, the properties of cognitive processes were thought to differ from physiological processes in the brain (Cartesian ontology). This tradition can be traced back to rationalist thinkers such as Descartes and Leibniz. Today, remnants of their theories continue to emerge in current cognitive sciences. There is still considerable resistance to acknowledging that cognition can be linked with the body in the same way as other physiological processes. Such resistance can be found in recent literature from Mahon (2015) and Mahon and Caramazza (2008), who argue that cognition is a phenomenon too complex to be explained by embodiment, primarily because their research does not seem to show a perfect connection between sensorimotor areas and higher cognitive processes. However, this evidence could only be used as a case against strong embodiment, which proposes that sensorimotor areas can sufficiently explain higher cognitive processes (Gallagher, 2005; Shapiro, 2014). Another problem with rejecting some types of embodied cognition is that there are no other testable hypotheses to study cognitive processes experimentally. The modular system (Fodor, 1983) or the computer analogy would be one of the most consistent theoretical frameworks against embodied cognition. Instead of proposing that bodily experience is the fundamental element that defines cognition, this framework proposes that symbols are in fact its foundation. This view holds that concepts are analysed based on formal abstract models that are completely unrelated to body and brain regions that govern interactions with the environment (Gallese \& Lakoff, 2005). However, current evidence shows that higher cognitive processes are not necessarily built on symbols, and that they can be grounded in the measurable activation of synapses (Gallese, Fadiga, Fogassi, \& Rizzolatti, 1996).

A further problem with the modular system is that by nature it is largely epistemological. As science demands, material objects and events are studied through hypotheses that can be tested empirically (Bunge, 1999; Popper, 2005). This statement might appear somewhat rudimentary, yet this is precisely the problem with the modular system. By taking this empirical and often sterile approach, measurements are produced that can be inconclusive or at best highly questionable. Instead, the embodiment approach offers more methodological possibilities for experimental and psychometrical testing due to its congruence with a more mechanistic vision of the mind. The following sections will illustrate this by clarifying some of the fundamental concepts and problems within the embodiment approach.

\section{Grounded experience}

The terms grounded experience or grounded cognition are used almost interchangeably. Despite its apparent simplicity, the term "grounded" requires clarification. In this context, "grounded" implies that cognitive phenomena such as memory, cognition, reasoning, social ranking, and even moral values are mostly mediated and shaped by our everyday life experience (Barsalou, 1999, 2008; Gibbs, 2006). This understanding is a radical departure from the "mind-as-a-computer" approach. Grounded cognitive processes are a return to the ideas of Hume, Berkeley, and other English empiricists, who suggest that 
the only experiences or impressions of reality we have are acquired through our senses (Hume, 1904). However, grounded experience does not suggest that Locke's tabula rasa is an acceptable position. There is also evidence that monkeys and non-human apes are capable of grounding their experience by creating metaphorical maps of their social groups, associating time with space dimensions, or showing sensorimotor brain activation when seeing their peers perform different tasks (Dahl, Rasch, Tomonaga, \& Adachi, 2013; Lakoff \& Núñez, 2000; Merritt, Casasanto, \& Brannon, 2010; Sigala, Gabbiani, \& Logothetis, 2002). In humans, another example of grounding can be found in cross-linguistic research, which shows that the understanding of some concepts (e.g. emotion) is closely related to the perception of physical space (Montoro, Contreras, Elosúa, \& Marmolejo-Ramos, 2015; Salgado-Montejo et al., 2016). Therefore, it is reasonable to hypothesise that, while some elements of human cognition are more or less universal, they are still grounded in a material reality. The majority of these findings discard the modular system in order to work with an embodiment approach. Further, the modular system is better understood as an integrated set of areas that work together in cognitive processing. Grounded cognitive processes will consequentially produce grounded concepts, meaning that their symbolic components are not as relevant (as suggested by computationalism). For example, the concept of time is an abstraction in and of itself but, expressed linguistically, is a concrete object: "we have time", "we are running out of time", or "I do not enjoy my time here". In these examples, time is grounded as a "thing", and is experienced as if it were an object or event (for more examples see Lakoff \& Johnson, 1980; Marmolejo-Ramos, Khatin-Zadeh, Yazdani-Fazlabadi, Tirado, \& Sagi, 2017, for a recent proposal see).

\section{Embodied experience}

By definition, embodiment means that all cognitive processes have sensorimotor properties (Barsalou, 2008; Gallese \& Lakoff, 2005; Gibbs, 2006). The paradigm of embodiment was initially studied as part of phenomenology. Husserl, Heidegger, and particularly Merleau-Ponty (1942/1967) suggested that the body was an object somehow attached to the rest of the empirical world, and that experience was intrinsic to the body. Thus, phenomenologists rejected a symbolic interpretation of experience (Shapiro, 2014). It is difficult to know with more detail what phenomenology means using terms such as object, Dasein (being there), or the flesh, due to its obscure writing and the exclusive use of introspective qualitative methods (see Brown, Cromby, Harpe, Johnson, \& Reavey, 2011 , for an example). Despite these origins, the embodiment approach has evolved significantly in the past 20 years to the point that we can now understand embodiment as a crucial part of phenomenology. As Beaton
(2016), says: "An externalist account of perceptual experience actually matches our first-person phenomenology better than any non-externalist account ever could. This is relevant because I am comparing direct realism to representationalism and to radical constructivism, each of which, in its own way, denies that external objects can play any constitutive role in experience." (Beaton, 2016). Embodiment that is more weak or graded in nature argues for more nuanced terminology such as "convergence zones", "modal content", and "gradiations in grounding" (see Chatterjee, 2010; Meteyard, Cuadrado, Bahrami, \& Vigliocco, 2012).

This idea that bodily states define the posibilities of mental action is not new; it was examined by James (1894) over a century ago. Since we cannot detach from our bodies, it stands to reason that there are no grounded experiences without embodied experiences. Therefore, our grounded experiences are being mediated at some point by our sensorimotor system. Despite the volume of evidence, the embodiment approach can still be questioned in that sensorimotor activation does not always occur (see Binder \& Desai, 2011; Mahon \& Caramazza, 2005).

Embodiment challenges the "mind-as-a-computer" metaphor of cognition in that, to have proper cognitive processes, an organism must have a body. As Lakoff and Johnson (1980) argue, computers do not have bodies. Therefore, they cannot develop authentic cognition or, at least, a form of cognition that would resemble that of humans. If cognitive processes are indeed part of the body like any other physiological mechanism, there is little merit beyond pedagogic purposes in using computer analogies or borrowed concepts (e.g. encoding, computations, information or modulation).

The relationship between body and environment is the intersection where grounded cognition and embodiment meet. The environment presents the objects or events that can be perceived by the body, as Gibson (1979) argued rather extensively. Ecological perception is a theory that embraces embodiment and embeddedness, giving the environment a predominant role in cognition. The possibilities of our cognition are limited by our environment, body mechanisms and brains (Chemero $\&$ Silberstein, 2008). However, there are traces of the modulatory system at work when hypotheses create a dichotomy between the body and the brain, as if they were isolated entities (see Fodor, 1983; Goldinger, Papesh, Barnhart, Hansen, \& Hout, 2016; Mahon, 2015). This is not only a return to a Cartesian ontology, but also a contradiction of elemental human anatomy and physiology (Boulpaep et al., 2009). Since body and brain are a series of subsystems that interact with each other, there is no way to understand the function of one without the other, nor is there a possibility to understand modules (if they in fact exist) that evolve without taking 
into account the environment.

\section{Relationship of embodiment with the identity hypothesis (emergent materialism)}

So, the question can then be asked: what type of philosophy of the mind best fits graded or weak embodiment? It could be argued that the identity hypothesis (also known as psychophysiological monism) is a potential answer. This hypothesis suggests that psychological processes can be explained via physiological and environmental activity, and that the properties of the mind are the same as the properties of the body (Bunge, 1980). There are two variants of this hypothesis: eliminative materialism and emergent materialism. They both have their similarities - namely, that they view cognitive processes as entities dependent on the brain, and that these processes should not be viewed as merely metaphysical or isolated from bodily functions. However, they also have their differences.

Eliminative materialism claims that everything mental can be explained via physiological structures, and that any psychological phenomenon is a result of inadequate categorical explanation (folk psychology). Hence, it suggests that cognitive sciences should focus only on the measurable and atomised brain parts that are related to any example of what we refer to as psychological phenomena (for a deeper review, see Churchland, 1989; Dennett, 1991). There are two major problems with this approach. Firstly, eliminative materialism follows the same theoretical path as radical behaviorism (Skinner, 1977); that is, there is no body-mind issue because there was no mind ("mental organ"), and all important stimuli are external to the body. Under this approach, there is no possibility of building a theory of cognition or to understand physical behavior as part of a cohesive system. The second problem is that eliminative materialism assumes that internal and atomised biological, chemical, or physical explanations have a sufficient degree of causality to explain psychological phenomena. This notion does not appear to explain cognitive processes as a whole. It also does not encourage psychological or physiological research since, according to eliminative materialism, there is theoretically no such thing as mental phenomena.

Emergent materialism consists of three principles that suit the embodiment approach, at least in its weak or graded version: a) all cognitive processes are states or events that happen in the brain and body; b) these processes are emergent relative to those of cellular components of the brain; and c) psychophysical or psychosomatic relations are interactions between different brain subsystems (neural connections) and the rest of the body (Bunge, 1977, 1978). The link between the embodiment approach and emergent materialism (or identity hypothesis) lies in their common interest in studying emergent properties without abusing the concept of causality. They do not see the body and the mind as separate entities, nor do they believe that the properties of cognition are reduced to isolated (or even non-existent) components. Rather, they believe the interaction within different body systems are what we define, in folk psychology, as cognitive processes. However, emergent materialism is a hypothesis, not a theory, because it lacks concrete predictive power in particular situations. By this definition, experimental research is able to offer a more thorough theoretical definition of embodiment.

Embodiment also aligns with emergent materialism in its epistemological dimension, as it studies material entities such as the brain, the senses, and the nervous system, while not limiting itself to symbols or behaviour. In this sense, it salvages the best of traditional behaviourism (i.e. the need to study observable objects and events) and the best of classical cognitivism (i.e. not reducing cognition to properties and functions that are indestinguishable). Therefore, the embodiment approach is compatible with a philosophy of the mind that offers deeper opportunities for research, as opposed to the Cartesian-embedded understanding of the "mind-as-a-computer".

We can then conclude that there is no need for extreme reductionism by atomising cognition, as proposed by eliminative materialism. Rather, cognition can be studied as a system without major complications. For example, we can study the stomach or intestines individually, or the digestive system as a whole. We can study entire ecosystems, or the particular species that compose them. We can study the orbit of the planet, or the entire movement of the solar system. By the same token, we can study brain areas or biochemical reactions either separately or as part of wider interactions that include the whole human body, all without losing any experimental or theoretical rigour. Despite the congruence that the embodiment approach has with a more empirically testable philosophy of the mind, shortcomings still remain.

\section{Current limitations}

Due to its sensitive experimental nature, the embodiment approach has its advantages when carrying out empirical research, particularly in the case of psychometric research (Longo, Schüür, Kammers, Tsakiris, \& Haggard, 2008). However, it is only beginning to answer questions within cognitive science, and it is not a concrete solution to the mind-body problem. As it fails to align with traditional cognitive approaches, embodiment tends to be categorised as an "umbrella" term in current research contexts. Thus, these limitations must be overcome in order to achieve a better explanation of the mechanisms related to cognition. 


\subsection{Abstract concepts}

As Barsalou (2008) suggested, there is a need for further research that links sensorimotor properties to abstract concepts. The sensorimotor theory aims to demonstrate that perception is directly related to understanding. It argues, firstly, that we can perceive only what we can understand; and secondly, and more strongly, that perception is an active process of understanding our engagment with the world. It is important to note that, in this approach, there is no intermediate thing called "experience" that understanding engages with; experience is the active engagement of understanding. Note also that the "understanding" in question is not an abstract, intellectual understanding; but rather a more fundamental, procedural knowledge, including the crucial knowledge of how to act and interact (Beaton, 2016).

Some studies have demonstrated clear links between concrete and abstract domains by asking participants to perform various body movements, or to place valenced objects in space (positive items go "up", negative items go "down"). This has been shown to have an effect on memory, emotional state, and semantic space processes (Casasanto, 2009; Salgado-Montejo et al., 2016; Vigliocco, Vinson, Lewis, \& Garrett, 2004). Lakoff and Johnson (1980) proposed that something as abstract as metaphors can be grounded in bodily experience. In this field of research, Casasanto and Boroditsky (2008) demonstrated the existence of an asymmetrical relationship between space and time. This indicates that people find it easier to create metaphors of time by mapping properties from the space concrete domain to the time abstract domain, rather than the other way around. Margolies and Crawford (2008) also linked emotional valence with metaphors of time that described movement. Eskine, Kacinik, and Prinz (2011) even found that moral and political judgement can be modulated by gustatory taste. (Casasanto, 2008) showed that stimuli placed closer in space were rated as more similar during conceptual judgment and less similar during perceptual judgment. These findings further reinforce the notion that cognition is embedded and embodied. In order to understand how concepts are created, we need to understand the relationship of the body and the environment rather than symbolic representations created in "modules".

This body of research supports the embodiment approach due to its high level of behavioral and mechanistic explanations. However, there are still many abstract concepts that must be tested in order to understand the extent to which embodied cognition can explain phenomena related to the mind. Additionally, the physiological mechanisms involved in transforming concrete knowledge to abstract knowledge are still generating much debate. Further research is needed that relates embodiment and abstract concepts to perceptual and motor modalities in order to give stronger support to the sensorimotor prin- ciple. It appears that neuroscientific research supports the weak embodiment hypothesis (see Meteyard et al., 2012 , for a review). Whether conceptual processing is abstract or concrete, cognitive processes are simulated in the brain before being manifested as behavior. Nevertheless, this event needs to be studied further at a synaptic level, as reducing all abstract concepts to sensorimotor brain areas contradicts other findings (Chatterjee, 2010). For a recent discussion in regard to embodiment and abstract concepts see Borghi et al. (2017).

\subsection{Theoretical fragmentation}

Embodiment has a range of implications. The most obvious proposition is that all cognitive processes happen in the body, and there is no abstract "mind" activating cognition. While perhaps simply a truism to some (Goldinger et al., 2016), it is a source of ongoing debate within the embodiment literature, as there is no clear consensus on what mechanisms are involved in embodied cognition and their dynamics at a neuronal level. However, the embodiment approach has been successfully applied to a wide range of psychological and neurological phenomena (see Shapiro, 2014, for a review). Radical and graded embodiment (Chatterjee, 2010; Varela, 1996), enactivism, simulations, external cognition, and extended cognition (Gover, 1996; Wilson, 2002) are all concepts found in the embodiment literature, either in isolation or opposition. Hence, the embodiment approach must solve its conceptual ambiguity to become a legitimate theory that explains and predicts cognitive processes.

We suggest embarking on a research path that encompasses experimental psychophysiology and cross-modal correspondences (that is, the compatibility effect between dimensions of a stimuli and different modalities) as a potential avenue to counter conceptual fragmentations. The psychophysiology of crossmodality studies brain mechanisms, their interactions with the rest of the body, the environment-senses, and sense-sense interactions (see Spence, 2011, for a review). There has been an increasing interest in the effect of synaesthetic congruency on multisensory information processing (Evans \& Treisman, 2009; Gallace \& Spence, 2006; Makovac \& Gerbino, 2010; Parise \& Spence, 2008) and cross-modal metaphors (Marks, 2004). A large body of research has indicated that people exhibit consistent cross-modal correspondences between different stimuli that imply very different sensory modalities. For example, people consistently match high-pitched sounds with small, bright objects that are located high up in space (Salgado-Montejo et al., 2016; Spence, 2011). There is no need to propose more 'computational models', where the concepts tend to be obscure, immaterial, and reliant on external behavior. As Bunge (1980) puts it, behavior is only the "tail" of the whole body-environment interaction. 


\subsection{Representations vs. non-representations}

The concept of representation is unclear in both cognitive and embodiment literature. There is no precise consensus as to whether representations are images, simulations, abstractions, bodily experiences, or even images of unexperienced objects (see Harnad, 1990, for a discussion). Therefore, differences among embodiment approaches are most likely due to conceptual misunderstandings (see Gentsch, Weber, Synofzik, Vosgerau, \& Schütz-Bosbach, 2016, for a review). This has split the embodiment approach between those who defend representations or weak embodiment (Alsmith \& De Vignemont, 2012; Barsalou, 1999; Goldman, 2012); and those who reject them completely - or strong embodiment (Chemero, 2009; Gallagher, 2005; Shapiro, 2014). However, much of this conceptual confusion can be avoided by simply applying a neuroscientific perspective to the problem. The representational embodiment view proposes that the brain is the most relevant mediator of cognitive processes, while the non-representational embodiment view proposes that musculoskeletal structures alone provide sufficient feedback for cognitive processes to arise (Gallagher, 2005). Furthermore, it argues that there is no need for representations to mediate between external and internal parts of the system, and that the perceptual system and its related physiological components is all that is required (Chemero, 2009; Gibson, 1979).

As most body movement is mediated by the brain, the representational embodiment view appears to hold the greatest consistency with elemental human physiology (Agur \& Dalley, 2009; Augustine et al., 2008). This view is also supported by experimental findings (Cardona et al., 2014; Gallese et al., 1996), where activation in the motor areas of the brain has been documented in tasks related to movement, emotion, and language. The non-representational embodiment view not only has consistency problems in relation to basic anatomy, it is also highly speculative. Arguably, the non-representational embodiment view could claim that basic reflexes constitute an example of peripheral sensory organs, as they provide sufficient feedback to automatically and unconsciously execute movement in the absence of semantic representation. For example, reflex circuitry can mediate the withdrawal of a limb that has been exposed to a painful stimulus. Stimulation of nociceptive receptors leads to the activation of local circuits at the medullary level, causing withdrawal of the limb. While withdrawal happens before we become aware of pain, the reflex pathway receives input from several different sources. Thus, under certain conditions, descending pathways can suppress withdrawal from painful stimuli.

Higher cognitive functions that are largely executed by the brain's frontal lobe cannot be explained by the extension of cognition to peripheral structures (Augustine et al., 2008; Frith \& Dolan, 1996), so it is important to rigorously define which physiological mechanisms are directly related to cognitive processes. If we follow the logic of the non-representational embodiment view, what then are its conceptual limitations? Can we say that digestion, breathing, or cardiac regulation are components of cognitive processes? Cognition, like other psychological terms, lacks a physiologically-defined concept, which leaves the term open to speculation. That said, the nonrepresentational embodiment view does seem to be useful in the burgeoning field of artificial intelligence (see Clark, 1997, 1998; Clark \& Chalmers, 1998).

\subsection{Brain injuries and neuroplasticity}

According to Mahon (2015), due to a lack of evidence in patients with brain damage embodied cognition is not a paradigm worth embracing. Studies have shown that patients who suffered damage did not lose cognitive skills related to the affected area, at least not severely (Binder \& Desai, 2011; Chatterjee, 2010; Mahon \& Caramazza, 2005). Because these findings seemed to suggest little connection between brain activity and cognitive processes, they were used to critique the embodiment approach. However, this statement begs clarification on three accounts: a) the brain is a system that inherently seeks to compensate for injuries (Cardona et al., 2014; Price \& Friston, 2002); b) there is extensive research that presents evidence in favor of brain plasticity (Augustine et al., 2008); and c) the embodiment approach allows for the possibility that cognitive processes engage various parts of the body, not only the brain (see Freund et al., 2016).

Glenberg (2015) also addressed these critics by explaining that the modal system does not have a relationship with any one brain area, but is distributed via synapses around the brain. This is congruent with the bulk of neuroscientific research showing that when a brain area suffers an ablation, other areas compensate for the damage (Augustine et al., 2008; Goldman, 2012). There is also evidence to suggest that embodiment and cross-modality are universally linked, even if subjects do not show explicit symptoms. For example, a study focusing on vision-touch synaesthesia found that the somatosensory cortex was activated when participants observed a human face or neck being touched, both in those with and without synesthesia (Blakemore, Bristow, Bird, Frith, \& Ward, 2005). Further research on the relationship between cognition and cross-modality is required, not only to understand the relationship between specific brain areas and cognitive processes, but to understand how they work together systematically, especially when damage has occurred.

\section{Conclusion}

While computer-based cognitive theories are certainly useful in the study of human behaviour and artificial in- 
telligence, they are still entrenched in Cartesian ontology. Hence, they are not the most suitable way in which to view cognitive processes. On the other hand, the embodiment approach incorporates elements ideal for cognitive research, such as grounded cognition, empiricism, physicalism, and experimental research. This approach also dovetails with the concept of emergent materialism. We believe that weak embodiment offers the most compelling evidence towards this new paradigm, while strong embodiment is problematic from both conceptual and physiological standpoints. Despite fragmented theoretical evidence that supports embodiment in a diverse range of contexts, we suggest that more research is needed in the areas of psychophysiology and cross-modal correspondence. It is crucial that deeper knowledge is generated about the relationship between the brain, body, and environment in order to avoid introspective phenomenological speculations and untestable theories. Thus, we propose that weak embodiment is the strongest approach to take.

Acknowledgements The authors thank Susan Brunner and Rosie Gronthos for proofreading this manuscript and Johanna Vestlund for discussing ideas related to the content of this manuscript.

Declaration of conflicting interests The author(s) declared no potential conflicts of interest with respect to the research, authorship, and/or publication of this article.

Funding The authors received no financial support for the research, authorship, and/or publication of this article.

\section{References}

Agur, A. M. R., \& Dalley, A. F. (2009). Grant's atlas of anatomy. Lippincott Williams \& Wilkins.

Alsmith, A. J. T., \& De Vignemont, F. (2012). Embodying the mind and representing the body. Review of Philosophy and Psychology, 3(1), 1-13.

Augustine, J., Fitzpatrick, D., Hall, W., LaMantia, A., McNamara, J., Mooney, R., \& Williams, S. (2008). Neuroscience. Sunderland, MA.

Barsalou, L. (1999). Perceptions of perceptual symbols. Behavioral and Brain Sciences, 22(4), 637-660.

Barsalou, L. (2008). Grounded cognition. Annu. Rev. Psychol., 59, 617-645.

Barwise, J., \& Perry, J. (1983). Situations and attitudes (M. Cambridge, Ed.). MIT Press.

Beaton, M. (2016). Sensorimotor direct realism: how we enact our world. Constructivist Foundations, 11(2), 265-276.
Binder, J., \& Desai, R. (2011). The neurobiology of semantic memory. Trends in Cognitive Sciences, 15(11), 527-536.

Blakemore, S.-J., Bristow, D., Bird, G., Frith, C., \& Ward, J. (2005). Somatosensory activations during the observation of touch and a case of vision-touch synaesthesia. Brain, 128(7), 1571-1583.

Borghi, A., Binkofski, F., Castelfranchi, C., Cimatti, F., Scorolli, C., \& Tummolini, L. (2017). The challenge of abstract concepts. Psychological Bulletin, 143(3), 263-292.

Boulpaep, E., Boron, W., Caplan, M., Cantley, L., Igarashi, P., Aronson, P., \& Moczydlowski, E. (2009). Medical physiology a cellular and molecular approach. Signal Transduct, 48, 27.

Brooks, R. (1991). Intelligence without representation. Artificial Intelligence, 47(1-3), 139-159.

Brown, S., Cromby, J., Harpe, D., Johnson, K., \& Reavey, P. (2011). Researching "experience": Embodiment, methodology, process. Theory $\&$ Psychology, 21(4), 493-515.

Bunge, M. (1977). Emergence and the mind. Neuroscience, 2(4), 501-509.

Bunge, M. (1978). The mind-body problem in the light of contemporary biology (with Rodolfo Llinás). In 16th world congress of philosophy: Section papers (pp. 131-133).

Bunge, M. (1980). The mind-body problem: A psychobiological approach. Pergamon: Oxford.

Bunge, M. (1999). Social science under debate: A philosophical perspective. University of Toronto Press.

Cardona, J., Kargieman, L., Sinay, V., Gershanik, O., Gelormini, C., Amoruso, L., ... others (2014). How embodied is action language? Neurological evidence from motor diseases. Cognition, 131(2), $311-322$.

Casasanto, D. (2008). Similarity and proximity: When does close in space mean close in mind? Memory E) Cognition, 36(6), 1047-1056.

Casasanto, D. (2009). Embodiment of abstract concepts: good and bad in right-and left-handers. Journal of Experimental Psychology: General, 138(3), 351.

Casasanto, D., \& Boroditsky, L. (2008). Time in the mind: Using space to think about time. Cognition, $106(2), 579-593$.

Chatterjee, A. (2010). Disembodying cognition. Language and Cognition, 2(1), 79-116.

Chemero, A. (2009). Radical embodied cognitive science. US: MIT Press.

Chemero, A., \& Silberstein, M. (2008). After the philosophy of mind: Replacing scholasticism with science. Philosophy of Science, 75(1), 1-27.

Churchland, P. (1989). Neurophilosophy: Toward a unified science of the mind-brain. MIT Press. 
Clark, A. (1997). Being there: Putting brain, body and mind together again. MIT Press.

Clark, A. (1998). Embodiment and the philosophy of mind. Royal Institute of Philosophy Supplements, 43, 35-51.

Clark, A., \& Chalmers, D. (1998). The extended mind. Analysis, 58(1), 7-19.

Dahl, C., Rasch, M., Tomonaga, M., \& Adachi, I. (2013). The face inversion effect in non-human primates revisited-an investigation in chimpanzees (pan troglodytes). Scientific Reports, 3, 2504.

Dennett, D. (1991). The future of folk psychology: Intentionality and cognitive science. In (pp. 135-148).

Eskine, K., Kacinik, N., \& Prinz, J. (2011). A bad taste in the mouth: Gustatory disgust influences moral judgment. Psychological Science, 22(3), 295-299.

Evans, K. K., \& Treisman, A. (2009). Natural crossmodal mappings between visual and auditory features. Journal of Vision, 10(1), 6-6.

Fodor, J. (1975). The language of thought. Harvard University Press.

Fodor, J. (1983). The modularity of mind: An essay on faculty psychology. MIT Press.

Fodor, J., \& Pylyshyn, Z. (1981). How direct is visual perception?: Some reflections on Gibson's ecological approach (Vision and Mind. Cambridge ed.; A. Noë, Ed.). MA: MIT Press.

Freund, P., Friston, K., Thompson, A., Stephan, K., Ashburner, J., Bach, D., ... others (2016). Embodied neurology: an integrative framework for neurological disorders. Brain, 139(6), 1855-1861.

Frith, C., \& Dolan, R. (1996). The role of the prefrontal cortex in higher cognitive functions. Cognitive Brain Research, 5(1-2), 175-181.

Gallace, A., \& Spence, C. (2006). Multisensory synesthetic interactions in the speeded classification of visual size. Perception \& Psychophysics, 68(7), 1191-1203.

Gallagher, S. (2005). How the body shapes the mind. Clarendon Press.

Gallese, V. (2003). The manifold nature of interpersonal relations: the quest for a common mechanism. Philosophical Transactions of the Royal Society of London B: Biological Sciences, 358(1431), 517-528.

Gallese, V., Fadiga, L., Fogassi, L., \& Rizzolatti, G. (1996). Action recognition in the premotor cortex. Brain, 119(2), 593-609.

Gallese, V., \& Lakoff, G. (2005). The brain's concepts: The role of the sensory-motor system in conceptual knowledge. Cognitive Neuropsychology, 22(3-4), 455-479.

Gentsch, A., Weber, A., Synofzik, M., Vosgerau, G., \& Schütz-Bosbach, S. (2016). Towards a common framework of grounded action cognition: Relating motor control, perception and cognition. Cognition, $146,81-89$.

Gibbs, R. (2006). Embodiment and cognitive science. New York: Cambridge University Press.

Gibson, J. (1979). The ecological approach to visual perception. New Jersey: Lawrence Erlbaum Associates.

Glenberg, A. (2015). Few believe the world is flat: How embodiment is changing the scientific understanding of cognition. Canadian Journal of Experimental Psychology/Revue canadienne de psychologie expérimentale, 69(2), 165-171.

Goldinger, S., Papesh, M., Barnhart, A., Hansen, W., \& Hout, M. (2016). The poverty of embodied cognition. Psychonomic Bulletin \& Review, 23(4), 959-978.

Goldman, A. (2012). A moderate approach to embodied cognitive science. Review of Philosophy and Psychology, 3(1), 71-88.

Gover, M. (1996). The embodied mind: Cognitive science and human experience (book). Mind, Culture, and Activity, 3(4), 295-299.

Harnad, S. (1990). The symbol grounding problem. Physica D: Nonlinear Phenomena, 42(1-3), 335-346.

Hume, D. (1904). An enquiry concerning human understanding (T. K. Paul, Ed.). Open Court Publishing.

James, W. (1894). Discussion: The physical basis of emotion. Psychological Review, 1(5), 516.

Lakoff, G. (2014). Mapping the brain's metaphor circuitry: Metaphorical thought in everyday reason. Frontiers in Human Neuroscience, 8, 958. doi: doi:10.3389/fnhum.2014.00958

Lakoff, G., \& Johnson, M. (1980). The metaphorical structure of the human conceptual system. Cognitive Science, 4(2), 195-208.

Lakoff, G., \& Núñez, R. (2000). Where mathematics comes from: How the embodied mind brings mathematics into being. Basic Books.

Longo, M., Schüür, F., Kammers, M., Tsakiris, M., \& Haggard, P. (2008). What is embodiment? A psychometric approach. Cognition, 107(3), 978-998.

Mahon, B. (2015). The burden of embodied cognition. Canadian Journal of Experimental Psychology/Revue canadienne de psychologie expérimentale, 69(2), 172.

Mahon, B., \& Caramazza, A. (2005). The orchestration of the sensory-motor systems: Clues from neuropsychology. Cognitive Neuropsychology, 22(3-4), 480-494.

Mahon, B., \& Caramazza, A. (2008). A critical look at the embodied cognition hypothesis and a new proposal for grounding conceptual content. Journal of Physiology-Paris, 102(1-3), 59-70.

Makovac, E., \& Gerbino, W. (2010). Sound-shape con- 
gruency affects the multisensory response enhancement. Visual Cognition, 18, 133-137.

Margolies, S., \& Crawford, L. (2008). Event valence and spatial metaphors of time. Cognition and Emotion, 22(7), 1401-1414.

Marks, L. E. (2004). Handbook of Multisensory Processes. In C. S. G. A. Calvert \& B. E. Stein (Eds.), (pp. 85-105). Cambrigde: MIT Press.

Marmolejo-Ramos, F., Khatin-Zadeh, O., YazdaniFazlabadi, B., Tirado, C., \& Sagi, E. (2017). Embodied concept mapping: blending structuremapping and embodiment theories. Pragmatics \&6 Cognition, 24(2), 164-185.

Merritt, D., Casasanto, D., \& Brannon, E. M. (2010). Do monkeys think in metaphors? Representations of space and time in monkeys and humans. Cognition, $117(2), 191-202$.

Meteyard, L., Cuadrado, S. R., Bahrami, B., \& Vigliocco, G. (2012). Coming of age: A review of embodiment and the neuroscience of semantics. Cortex, 48(7), 788-804.

Montoro, P., Contreras, M., Elosúa, M., \& MarmolejoRamos, F. (2015). Cross-modal metaphorical mapping of spoken emotion words onto vertical space. Frontiers in Psychology, 6, 1205. doi: 103389/fpsyg.2015.01205

Parise, C., \& Spence, C. (2008). Synesthetic congruency modulates the temporal ventriloquism effect. Neuroscience Letters, 442(3), 257-261.

Popper, K. (2005). The logic of scientific discovery. Routledge.

Price, C., \& Friston, K. (2002). Degeneracy and cognitive anatomy. Trends in Cognitive Sciences, 6(10), 416-421.

Salgado-Montejo, A., Marmolejo-Ramos, F., Alvarado, J. A., Arboleda, J. C., Suarez, D. R., \& Spence, C. (2016). Drawing sounds: representing tones and chords spatially. Experimental Brain Research, 234(12), 3509-3522.

Shapiro, L. (2014). The Routledge Handbook of Embodied Cognition. Routledge.

Sigala, N., Gabbiani, F., \& Logothetis, N. K. (2002). Visual categorization and object representation in monkeys and humans. Journal of Cognitive Neuroscience, 14(2), 187-198.

Skinner, B. F. (1977). Why i am not a cognitive psychologist. Behaviorism, 5(2), 1-10.

Spence, C. (2011). Crossmodal correspondences: A tutorial review. Attention, Perception, 8 Psychophysics, 73(4), 971-995.

Varela, F. (1996). Neurophenomenology: A methodological remedy for the hard problem. Journal of Consciousness Studies, 3(4), 330-349.

Vigliocco, G., Vinson, D., Lewis, W., \& Garrett, M. (2004). Representing the meanings of object and action words: The featural and unitary semantic space hypothesis. Cognitive Psychology, 48(4), 422-488.

Wilson, M. (2002). Six views of embodied cognition. Psychonomic Bulletin \& Review, 9(4), 625-636. 